\title{
Identification and hemolytic activity of jellyfish (Rhopilema sp., Scyphozoa: Rhizostomeae) venom from the Persian Gulf and Oman Sea
}

\author{
HOSSEIN JAFARI ${ }^{1}$, HOSSEIN HONARI ${ }^{2, \boldsymbol{v}}$, JAMIL ZARGAN ${ }^{2}$, SAEID TAMADONI JAHROMI ${ }^{\mathbf{3}}$ \\ ${ }^{1}$ Program of Nanobiotechnology, Department of Biology, Faculty of Basic Sciences, Imam Hossein University, Tehran, Iran \\ ${ }^{2}$ Department of Biology, Faculty of Basic Sciences, Imam Hossein University, Tehran, Iran. "email: honari.h2018@gmail.com \\ ${ }^{3}$ Persian Gulf and Oman Sea Ecology Research Center, Iranian Fisheries Sciences Research Institute, Agricultural Research Education and Extension \\ Organization (AREEO), Bandar Abbas, Iran
}

Manuscript received: 27 December 2018. Revision accepted: 31 March 2019.

\begin{abstract}
Jafari H, Honari H, Zargan J, Jahromi ST. 2019. Identification and hemolytic activity of jellyfish (Rhopilema sp., Scyphozoa: Rhizostomeae) venom from the Persian Gulf and Oman Sea. Biodiversitas 20: 1228-1232. The present study investigated the hemolytic capacity of the crude venom extracted from isolated nematocysts of Rhopilema sp. Scyphozoa: Rhizostomeae. Nematocyst was used at various concentrations to evaluate the hemolytic activity by using the nematocysts of human, mice, and sheep. Mean concentrationdependent hemolysis could be observed from $200 \mu \mathrm{g} / \mathrm{mL}$ of protein equivalents or higher with variable potencies in different species. The crude venom was analyzed using sodium dodecyl sulfate-polyacrylamide gel electrophoresis SDS-PAGE. Molecular weight with 3 clear bands including 45, 65 and $95 \mathrm{kDa}$ appeared to be the major protein components of the venom. The results of our experiments indicated that venom of Rhopilema sp. induces hemolysis in the studied species and determined that the increase in the amount of toxin has a positive correlation with the increase of cell lysis. This study showed that the venom of Rhopilema sp. may have many biologically active principles, which need further studies in the future.
\end{abstract}

Keywords: Venom, Nematocysts, Hemolytic assay, Rhopilema

\section{INTRODUCTION}

Jellyfish belong to the largest known Medusa in the Cnidaria phylum. Some of this species belonging to this phylum such as Rhopilema sp. are reported in the Persian Gulf (Qeshm island) and the Oman Sea (Bandar E- Jask). Their populations become very large in many seasons of the year (Jouiaei et al. 2015). Jellyfish blooming causes change in fisheries stock due to food competition. In current years, there have been many reports of jellyfish blooms in different parts of the world such as Italy, Turkey, and China. Such changes in the population and distribution have also been reported in the Persian Gulf and Oman Sea. (Daryanabard and Dawson 2008). Jellyfish blooms of various species have always interested the researchers since they often cause damage to swimmers. Most injured people do not need supplementary therapies and hospitals, but some show systemic complications and very few cases end in mortality. A change in the number of jellyfishes can lead to changes in marine ecosystems or destruction of the marine installations (Purcell et al. 2005, 2007). On the other hand, jellyfishes contain important compounds, especially collagen (Addad et al. 2011; Zhuang et al. 2009). In addition, at present, some invasive species such as Phyllorhiza sp. in the coastal waters have also severely affected the tourism industry in many coastal tourist spots (Johnson et al. 2005). The bloom of a giant jellyfish, Nemopilema nomurai, has caused fishery damages and danger to sea bathers in the waters of China, Korea, and Japan.

The objective of this research is to investigate the cytotoxic and hemolytic activities of crude venom extract of Rhopilema sp. using a number of in-vitro assays. Toxins resulting from some of the jellyfish species typically for the development of new drugs also have promising applications in cardiovascular medicine and target medicine of nerve molecular biology. Therefore, it is useful to study jellyfish venom which is beneficial in human health using animal studies. Such experiments in rat confirmed that jellyfish can be used to cure arthritis (Billingham et al. 1973). Other researchers have described that the various venoms from different jellyfish species have biological functions (Deshane et al. 2003). A few publications have dealt with the nematocyst toxins of Rhopilema sp. on the basis of a newly developed method for isolating undercharged nematocysts of these jellyfishes. The present study was performed to examine the biological properties of crude extracts from Rhopilema sp. from the Persian Gulf and Oman Sea.

\section{MATERIALS AND METHODS}

\section{Sampling}

Jellyfish medusae of the Rhopilema sp. were collected by diving from Bandar- E Jask in the southwest of Iran $\left(25 \circ 31 ' 51.81 " \mathrm{~N}\right.$ and $\left.47 \circ 49^{\prime} 11.86 " \mathrm{E}\right)$ throughout the coastal waters of the Oman Sea during September to November 2017 (Figure 1). These specimens were identified as Rhopilema sp. according to Kramp (1961) and Kitamura and Omori (2010). 


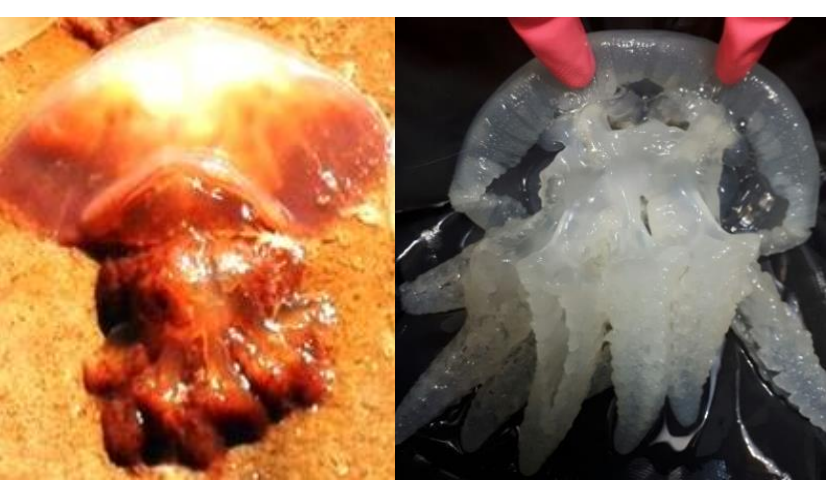

Figure 1. Rhopilema sp. morphotypes from the Oman Sea

\section{Isolation the venom}

Purification of isolated nematocyst preparation

The procedure made by Bloom et al. (1998) has been used to isolate the venom existing in nematocysts cells. For this purpose, tentacles were removed from live jellyfish. Then, tentacles were refrigerated in bottles with two volumes of seawater for one to four day. Once a day the containers were vigorously shaken and an aliquot filtered through a fine sieve. The decision to continue digestion of individual samples was based on microscopic examination of the filtered sediment and tentacles. The final sediments were then lyophilized and stored at $-70{ }^{\circ} \mathrm{C}$ until use.

\section{Preparation of nematocyst venom}

The powder resulting from the lyophilized nematocysts was dissolved (1: 6) in twice distilled water. Then the solution was examined by microscope to determine the amount of nematocysts cells. The Mechanical homogenization and sonication (Hielscher, UP100H (was performed in three periods of 20 seconds in dry ice. Next, the solution was centrifuged for 1 hour at 20,000 rpm. The solution was stored in $1 \mathrm{~mL}$ tubes in $-20{ }^{\circ} \mathrm{C}$.

\section{Determination of the concentration of extracted venom}

To determine the concentration of toxin, 10 microliters $(\mu \mathrm{L})$ of the solution was added to $1.5 \mathrm{~mL}$ tubes, and then the volume was brought to the final volume of $100 \mathrm{~mL}$. In another tube, only $100 \mu \mathrm{L}$ of distilled water was poured. Then, one $\mathrm{mL}$ of Bradford solution was added to each tube and kept at room temperature for 5 minutes. The absorbance was measured at $595 \mathrm{~nm}$ by a spectrophotometer (Shimadzu, UV-1280). The numbers obtained were compared with the standard curve and the protein concentration was calculated (Bradford 1976).

\section{Purification of venom using gel chromatography}

For partial purification of toxin, $1 \mathrm{~mL}$ of the raw venom was applied to a $3 \times 6 \mathrm{~cm}$ column of Sephadex G200 chromatography column using 5.05 molar buffer at $\mathrm{pH}=$
0.7 and then the absorption of the fractions was determined at $280 \mathrm{~nm}$.

\section{Investigating the poisoning rate}

The bioassay of lethality was conducted using clinically healthy mice $(25 \pm 2 \mathrm{~g})$. The mice were maintained in the laboratory in a healthy condition. Mice in triplicate were tested subcutaneously with different concentrations at 10 , 100,200 , and 300 micrograms of toxin which were dissolved at $5 \mathrm{mg} / \mathrm{mL}$ in phosphate buffer saline (PBS) in a final injection volume of $0.5 \mathrm{~mL}$. Control was maintained in each case by injecting an equal volume of PBS (pH 7.4). The time of injection and death, as well as behavioral changes before death were recorded for 24 hours. The results of the main test were calculated using PearsonCarver statistical method.

\section{Estimating the lytic activity}

Human, mouse, and sheep red blood cells were used to evaluate the lytic activity of the venom. Blood samples were transferred to the tubes containing anti-clot material. Then, $20 \mathrm{~mL}$ of phosphate buffer saline (PBS) was added (pH 7.4) to $1 \mathrm{~mL}$ of blood, and centrifuged at $5000 \mathrm{rpm}$ for 5 minutes at $4^{\circ} \mathrm{C}$. The supernatant was drained and recentrifuged at $5000 \mathrm{rpm}$ for 5 minutes. Finally, the erythrocytes were diluted up to $2 \%$. A 96 -well plate was used to determine the optical density. For each well, 300 $\mu \mathrm{L}$ of three types of blood cells (human, mice, and sheep) were inoculated with $2 \%$ dilution, and then $60 \mu \mathrm{L}$ of the sample extracted with concentrations of 50, 100, 200 and $400 \mu \mathrm{g} / \mathrm{mL}$ were added to each well. The mixture of poison and blood cells was placed at room temperature for 4 hours. Then, $150 \mu \mathrm{L}$ of the supernatant was removed from the wells and $150 \mu \mathrm{L}$ of the Bradford Reagent was added to each well. Finally, the absorbance was measured at 595 $\mathrm{nm}$. The wells containing blood cell suspension and wells with phosphate buffer saline were considered as negative and positive controls respectively (Bloom et al. 1998).

SDS-PAGE (sodium dodecyl sulfate-polyacrylamide gel electrophoresis) was used for the separation of proteins based on their molecular weight and their differential rates of migration through a sieving matrix (a gel) under the influence of an applied electrical field.

In this study total protein from protein compositions of studied jellyfish poison were isolated by Coomassie-stained $12 \%$ SDS-PAGE gel (Figure 2).

\section{RESULTS AND DISCUSSION}

\section{SDS-PAGE}

SDS-PAGE isolated protein compositions of studied jellyfish poison. Figure 1 shows that the venom contains proteins with different molecular weights, but most proteins are positioned in three molecular weights of 45,65 and $95 \mathrm{kDa}$ (Figure 1). 


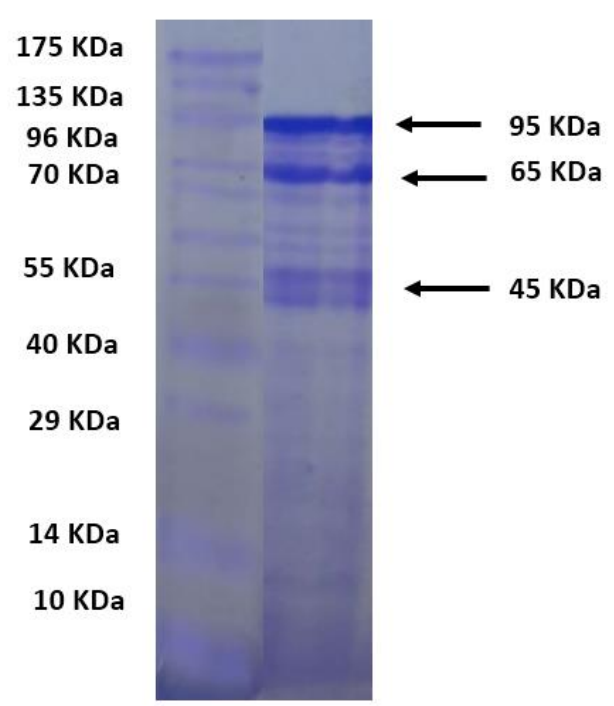

Figure 2. SDS-PAGE Gel (12\% polyacrylamide gel with Coomassie blue analysis showing Rhopilema sp. crude venom (right) and standard marker (left)

\section{Determination of the LD50 value}

The dilution series was used in the main test and subcutaneous injection was performed in 4 mice $(25 \pm 2 \mathrm{~g})$. Then the results were calculated using Pearson-Carver statistical method according to the equation below. Logarithm of the $100 \%$ death rate \pm (logarithmic coefficient $) /($ dose per sample number) $(\Sigma$ dead number $\mathrm{n} / 2)=\alpha \& \beta$. Eventually, the LD50 infusion rate for Balb/c was $0.45 \mu \mathrm{g} / \mathrm{kg}$.

\section{Hemolytic activity}

To evaluate the effect of the hemolytic effect, 50 to 800 $\mu \mathrm{g}$ of the venom was used to influence the human, mouse, and sheep blood cells. As shown in Figure 3, the amount of lysis of blood cells increased with the venom concentration. Concentrations of 250, 300 and 400 micrograms per $\mathrm{mL}$ caused a $50 \%$ lysis of blood cells of mice, humans, and sheep.

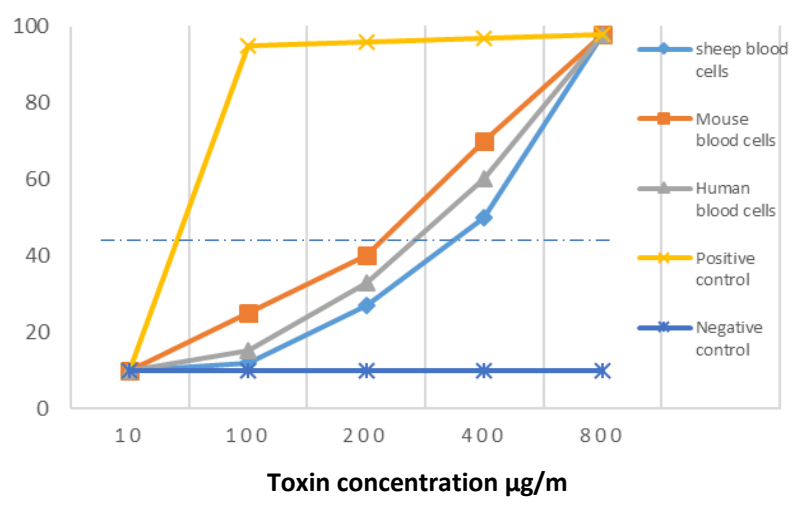

Figure 3. Hemolytic activity of Rhopilema sp. venom in mice, humans and sheep blood cells

\section{Extraction of total genomic DNA}

DNA was purified from each specimen (gonad tissue) using NEX ${ }^{\mathrm{TM}}$ Diagnostics kit following the manufacturer's protocol. Amplification of partial COI gene was conducted based on universal published primers by Folmer (1994). Forward, HCO 1490: (5' GGT CAA CAA ATC ATA AAG ATT TGG -3') and reverse HCO 2198: (5' TAA ACT TCA GGG TGA CCA AAA AAT CA -3').

The Neighbour-Joining tree is presented in Figure 3.All Iranian Rhopilema sp. in group sequences clustered into two distinct clusters and as sister groups with GenBank Rhopilema sp. This was in terms of the close relationships of Rhopilema sp. with $R$. esculentum with each pair forming a highly supported monophyletic group of $100 \%$ support.

\section{Discussion}

Pharmacology and toxicology of jellyfish venom have been investigated since 1960s and most of them have tried to extract its active components as a new natural source of medicine (Sugantahi et al 2001). In this research, an optimized method for isolating the venom has been presented. In order to evaluate the hemolytic activity of the venom, it was necessary to design a method that does not reduce the activity of the toxin. In this study, the properties of the hemolysis activity and poison detection of studied species have been investigated based on the technique using enzyme and lytic activities. According to lytic cell activity and cytotoxicity, the venom has been investigated for its efficacy as a possible anticancer drug (Maisano et al. 2013; Lee et al. 2011). The moon jellyfish has a strong fibrinolytic effect (Rastogi et al. 2102). The Persian Gulf and Oman Sea are areas where there are many varieties of marine jellyfishes. Different biodiversity in the Persian Gulf and Oman Sea has led to the creation of sea-bloom in some seasons, especially in spring and summer (Gharibi et al. 2016). In this study, the genus Rhopilema sp. was isolated and investigated. There are several methods for extracting jellyfish toxins, but modified method reported from Bloom et al. (1998) were used in this research. In this appropriate method, we obtained a suitable concentration that maintains the activity and active ingredients of the poison.

Marine jellyfish venom is sensitive to heat and its activity is greatly reduced by high temperature. But in this study, nematocysts isolated from sea jellyfish were lyophilized (Gamma model 1-16 LSCplus, Germany) by dry temperature. Performing proper sonication using acetate buffer containing $\mathrm{NaCl}$ and frozen tentacles in a phosphate buffer solution were performed based on the method of Nagai et al. (2002) in order to release the poison from nematocysts is also an important step for increasing the concentration of extracted poison. In this research, we introduced a modified method and proposed optimal conditions for venom extraction. This method has better efficacy than other methods, such as dialysis dehydration and ultrasound diffusion. In dialysis method, large amounts of poison proteins are usually lost, but its hemolytic activity is maintained. Conversely, in ultrasound diffusion method a good concentration of protein would be obtained, 
but its hemolytic activity is reduced ( $\mathrm{Li}$ et al. 2009). Molecular weight of venom protein was determined by SDS PAGE using standard protein markers and calculated. Three distinct bands with molecular weights of 45, 65 and $95 \mathrm{kDa}$ were recorded (Figure 1). In support, previous studies by Nagai et al. (2002), have reported $44 \mathrm{kDa}$ for Chiropsalmus quadrumanus. Also hemolytic components were studied by Keen and Crown (1969) who confirmed it to have molecular weight of $70 \mathrm{kDa}$ which compares to our present study showing $65 \mathrm{KDa}$.

In this study, the lytic effect of the venom on blood cells was evaluated in different species. Also, the effects of different concentrations of poison against human, sheep and mice blood cells were investigated. The results showed that increase in the amount of toxin has a direct relationship with the increase of hemolytic activity, while the increase in concentration does not increase uniformly with the amount of cell lysis (Figure 2). Walker et al (1977) determined the intravenous LD50 in mice (weight unspecified) to be $0.3 \mathrm{mg} / \mathrm{kg}$ and estimated the main toxin, which was a basic protein to have a molecular weight of approximately $70 \mathrm{KDa}$ Also, the type of blood cells is also a contributing factor in lysis effect (Ponce et al. 2013).
Rottini et al. (1995) showed that sheep red blood cells were more sensitive than mouse and human red blood cells, while Torres and Aguilar (2001) showed that the jellyfish Cassiopeia xamachana species has more lethargic effect on human red blood cells than on sheep red blood cells. Kang et al. (2009) investigated the lytic activity of $N$. nomuria on dogs, cats, guinea pigs, humans, and rabbits. They showed that the red blood cells of dogs were most sensitive. In the present study, we showed that the rate of lysis of blood cells in mice, sheep, and humans differs. Therefore, it can be summarized that the level of poison increases with the concentration level of venom and also in the same concentrations, it takes less time for the blood cells of the mouse to lyse compared to human and sheep blood cells. It can be suggested that the rate of blood cell lysis in studied jellyfish is unpredictable. This effect can be altered by changing the poison concentration of the venom (Kang et al. 2009). This study showed that the venom of Rhopilema sp. may have many biologically active principles, which need further studies in future. Thus, the biologically active compounds present in the venom of jellyfish are found to be useful tools for pharmacological research.

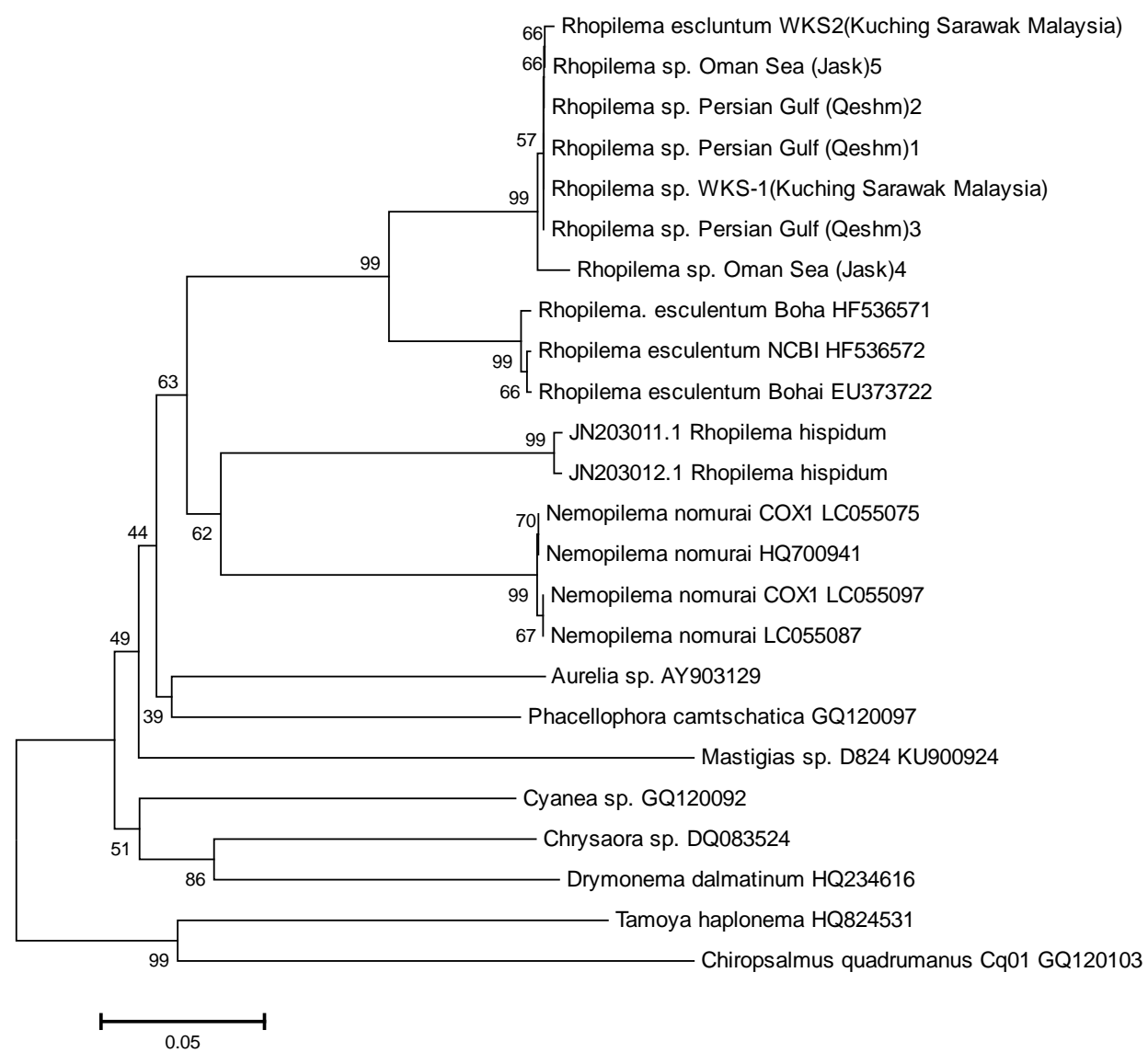

Figure 3. Neighbor-joining tree based on genetic distance analysis of COI sequences showing the genetic relationships of Rhopilema sp. and Rhopilema esculatum with similar genetic distances to the samples caught from Oman Sea area. Tamoya haplonema and Chiropsalmus quadrumanus species were used as outgroups. Scale shown refers to genetic distance based on nucleotide substitutions. Numbers at branching points are bootstrap support 
In this study, a suitable method for isolating the venom was introduced and it was shown that proteins of 45, 65 and $95 \mathrm{kDa}$ constitute the main venom proteins. Due to the presence of active compounds in the poison of studied species, and especially the hemolytic compounds, it can be considered for further investigations to produce recombinant proteins for some specific purposes. It was also found that the amount of cell lysis depends on the concentration of venom and the type of blood cells and varies in different species.

\section{ACKNOWLEDGEMENTS}

We would like to thank all the colleagues involved in sample collection and laboratory work. This research was funded by Department of Biology, Faculty of Basic Sciences, Imam Hossein University, Tehran, Iran under University Research Grant.

\section{REFERENCES}

Addad S, Exposito JY, Faye C, Ricard-Blum S, Lethias C. 2011. Isolation, characterization and biological evaluation of jellyfish collagen for use in biomedical applications. Marine Drugs 9: 967-83.

Billingham MEJ, Morley J, Hanson JM, Shipolini RA, Vernon CA. 1973. An Anti-Inflammatory peptide from bee venom. Nature 245 (5421): 163-164

Bloom DA, Burnett JW, Alderslade P. 1998. Partial purification of box jellyfish (Chironex fleckeri) nematocyst venom isolated at the beachside. Toxicon 36: 1075-1085.

Daryanabard R, Dawson MN. 2008. Jellyfish blooms: Crambionella orsini (Scyphozoa: Rhizostomeae) in the Gulf of Oman, Iran, 20022003. J Mar Biol Assoc UK 88: 477-483.

Deshane J, Garner CC, Sontheimer H. 2003. Chlorotoxin inhibits gliom cell invasion via matrix metalloproteinase-2. J Biol Chem 278 (6): 4135-4144.

Gharibi S, Nabipour I, Kim E, Ghafari SM, Hoseiny SM, Kamyab M, Seyedian R. 2016. Characterization and pharmacological activities of jellyfish, Chrysaora hysoscella captured in Bushehr Port. Iran Microbiol 10 (5): 7-10.

Johnson DR, Perry HM, Graham WM. 2005. Using nowcast mode currents to explore transport of non-indigenous jellyfish in the Gulf of Mexico. Mar Ecol Prog Ser 305: 139-146.

Kang C, Munawir A, Cha M, Sohn ET, Lee H, Kim JS, Yoon WD, Lim D, Kim E. 2009. Cytotoxicity and hemolytic activity of jellyfish
Nemopilema nomurai (Scyphozoa: Rhizostomeae) venom. Comp Biochem Physiol C Toxicol Pharmacol 150 (1): 85-90.

Keen TEB, Crone HD. 1969. The hemolytic properties of extracts of tentacles from the cnidarian Chironex fleckeri. Toxicon 7: 55-63.

Kimura M. 1980. A simple method for estimating evolutionary rates of base substitutions through comparative studies of nucleotide sequences. J Mol Evol 16 (2): 111-120.

Kitamura M, Omori M. 2010. Synopsis of edible jellyfishes collected from Southeast Asia, with notes on jellyfish fisheries. Plankton Benthos Res 5 (3): 106-118.

Kramp P L 1961. Synopsis of the medusae of the world. J Mar Biol Assoc UK (JMBA) 40: 7-382.

Lee H, Jung ES. et al. 2011. Scyphozoan jellyfish venom metalloproteinases and their role in the cytotoxicity. Toxicon 58: 277 284.

Li C, Yu H, Feng J, Chen X, Li P. 2009. Comparative analysis of methods for concentrating venom from jellyfish Rhopilema esculentum Kishinouye. Chinese J Oceanol Limnol 27 (1): 172-176.

Maisano M, Trapani MR, Parrino V, Parisi MG, Cappello T, D'Agata A, Benenati G, Natalotto A, Mauceri A, Cammarata M. 2013. Haemolytic activity and characterization of nematocyst venom from Pelagia noctiluca (Cnidaria: Scyphozoa. Italian J Zool 80: 168-176.

Nagai H, Takuwa-Kuroda K, et al. 2002. A novel protein toxin from the deadly box jellyfish (sea wasp, Habu-kurage) Chiropsalmus quadrigatus. Biosci.Biotechnol. Biochem 66: 97-102.

Ponce D, López-Vera E, Aguilar MB, Sánchez-Rodríguez J. 2013. Preliminary results of the in vivo and in vitro characterization of a tentacle venom fraction from the jellyfish Aurelia aurita. Toxins 5: 2420-2433.

Purcell JE, Uye SI. Lo WT. 2007. Anthropogenic causes of jellyfish blooms and their direct consequences for humans: a review. Mar Ecol Prog Ser 350, 153-174.

Purcell JE. 2005. Climate effects on formation of jellyfish and ctenophore blooms: a review. JMBA. 85, 461-476.

Rastogi A, Biswas S, Sarkar A, Chakrabarty D. 2012. Anticoagulant activity of moon jellyfish (Aurelia aurita) tentacle extract. Toxicon 60 (5): 719-723.

Rottini G, Gusmani L, Parovel E, Avian M, Patriarca P. 1995. Purification and properties of a cytolytic toxin in venom of the jellyfish Carybdea marsupialis. Toxicon 33 (3): 315-326.

Sugantahi K, Bragadeeswaran S, Kumaran N, Thangaraj S, Balasubramanian T. 2011. Biological and pharmacological activities of jelly fish Crambionelle stuhalmanni (Chun, 1896) and Chysaora quinquecirrha (Desor, 1848). Int J Pharm Pharm Sci 3 (2): 230-236.

Torres M, Aguilar MB. 2001. Electrophysiological and hemolytic activity elicited by the venom of the jellyfish Cassiopea xamachana. Toxicon 39, 1297-1307.

Walker MJA, Martinez TT, Godin DV. 1977. Investigations into the cardiotoxicity of a toxin from the nematocysts of the jellyfish, Cyanea capillata. Toxicon 15: 339-346.

Zhuang Y, Hou H, Zhao X, Zhang Z, Li B 2009. Effects of collagen and collagen hydrolysate from jellyfish (Rhopilema esculentum) on mice skin photoaging induced by UV irradiation. J Food Sci 74 (6): 183188. 